\title{
Analysis of Stress Asymmetric Distribution Law of Surrounding Rock of Roadway in Inclined Coal Seam: A Case Study of Shitanjing No. 2 Coal Seam
}

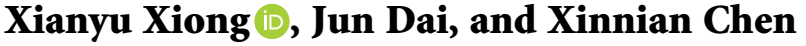 \\ School of Architecture and Civil Engineering, Xi'an University of Science and Technology, Xi'an, Shaanxi 710054, China \\ Correspondence should be addressed to Xianyu Xiong; xiongxianyu520@163.com
}

Received 10 March 2020; Revised 4 May 2020; Accepted 9 May 2020; Published 31 May 2020

Academic Editor: Yinshan Tang

Copyright (c) 2020 Xianyu Xiong et al. This is an open access article distributed under the Creative Commons Attribution License, which permits unrestricted use, distribution, and reproduction in any medium, provided the original work is properly cited.

\begin{abstract}
Asymmetrical deformation and failure characteristics of the surrounding rock at the right-angled trapezoidal roadway in the Shitanjing No. 2 mining area has created great difficulties in the stability control and support of the roadway. First, numerical simulations were applied to systematically analyze the distribution rules for vertical stress, horizontal stress, and failure characteristics of the roadway. Furthermore, verifications were conducted via laboratory model tests and practical engineering application. The results show that the two walls of the roadway, the roof, and the sharp corners demonstrate obvious asymmetric stress concentrations. The peak value of stress concentration in the low side (right wall) is significantly greater than that in the high side (left wall), and the distances from high and low sides of roadway to both walls of the roadway are obviously different. The two sharp corners, which are symmetrical along the same direction of the coal seam inclination, show obvious compressive stresses, while the opposite directions show obvious tensile stress regions at both sharp corners; further, maximum values of the compressive and tensile stresses appear at the two corners of the roadway roof, and their magnitudes vary with the change in inclination and ground stress.
\end{abstract}

\section{Introduction}

With the gradual exhaustion of high-quality coal resources and shrinkage of production in the eastern part of China in the 21st century, the focus of resource exploitation is shifting to the western part of China. The exploitation of coal resources plays an important role in facilitating energy efficiency in the western region [1-4]. The inclined coal seam reserves in the western region of China account for approximately $10.1 \%$ of the recoverable reserves, and there are high-quality coal seams with high mining value [5-7]. However, in the mining process of an inclined seam, the stress of the surrounding rock of the roadway is asymmetric owing to the influence of the inclination angle, which presents great difficulty in stability control and support engineering of the roadway [8-15].

Domestic and foreign researchers mainly focus on studying the asymmetric stress distribution characteristics of surrounding rocks in inclined seam roadways with large inclinations and steeply inclined seams, and the section forms are mostly rectangular and arch roadways. The current research results indicate that the stress distributions in the surrounding rocks of roadways exhibit obvious asymmetric characteristics for roadways excavated at large inclinations [16-20] and for steeply inclined [21-26] coal seams, the stress concentrations on the roof, two walls, and floor of a roadway is obviously different and increases with the inclination angle. Asymmetric deformation and failure of the roadway will occur due to asymmetric stress distribution of the surrounding rock [27]. Aiming at the asymmetric failure characteristics of the roof, two walls, and floor of the roadway (rectangular and arch); supporting measures were proposed in literature [1]. However, there are few studies on the asymmetric stress distributions of surrounding rocks in right-angled trapezoidal roadways with gently inclined coal seams at different inclination angles. 
Therefore, it is of great theoretical value and practical significance to conduct numerical simulations and analyze the stress asymmetry characteristics of right-angled trapezoidal roadways in gently inclined seams for stability evaluation.

In the inclined coal seam, the roadway is usually arranged along the roof, middle, and bottom of the coal seam. The location of the roadway in the coal seam is different, resulting in different cross-sectional shapes of the roadway. The Shitanjing No. 2 mining area is located in the western high-mountain area. It is a typical gently inclined coal seam with a dip angle of $18-27^{\circ}$. The thickness of the recoverable coal seam is $5.5-6.06 \mathrm{~m}$. The roadway is excavated along the roof of the coal seam to form a right-angled trapezoidal roadway. Taking the Shitanjing No. 2 mining area as the engineering background, theoretical analysis and numerical modeling with FLAC3D software are used to study the asymmetric distribution of surrounding rock stress in a right-angled trapezoidal roadway with an inclined dip angle. Based on the engineering background of the Shitanjing No. 2 mining area, in this research, the asymmetric stress distribution law of the surrounding rock of the rightangled trapezoidal roadway in different inclined seams is evaluated by theoretical analysis and numerical simulations using FLAC3D and verified via laboratory model tests and practical engineering application, which provide the scientific basis for the selection of supporting schemes for the right-angled trapezoidal roadway in this area.

\section{Analysis of Asymmetric Characteristics of the Stress in the Surrounding Rocks of the Roadway}

Numerous scholars have discovered that after the excavation of an inclined coal seam roadway, the stress redistribution around the roadway exhibits obvious asymmetric characteristics, and the stress distribution between the two walls of the roadway and the roof and floor is obviously different under the action of the overlying strata load [28-30]. As can be observed from Figure 1, the stress acting on the roadway is characterized by the shear stress $\sigma_{\mathrm{x}}$ along the inclined direction of the coal seam and the compressive stress $\sigma_{\mathrm{y}}$ perpendicular to the coal seam owing to the influence of the dip angle of the seam. The high side is subjected to a tensile force $\sigma_{\mathrm{x}}$ parallel to the direction of the coal body, while the low side is subjected to a squeezing force $\sigma_{\mathrm{y}}$ (Figure 1).

This asymmetry and nonhomogeneous stress state lead to stress concentration peak value on the right wall (low side) being greater than that on the left wall (high side), and the distances from the points with the peak stress concentrations at the high and low sides to both walls of the roadway are different (Figure 2). According to the formula for the width of the stress limit equilibrium zone, the distance between the stress concentration areas $A$ and $B$ and the wall of the roadway can be calculated as $x_{A}$ and $x_{B}$, respectively, as shown in equations (1) and (2).

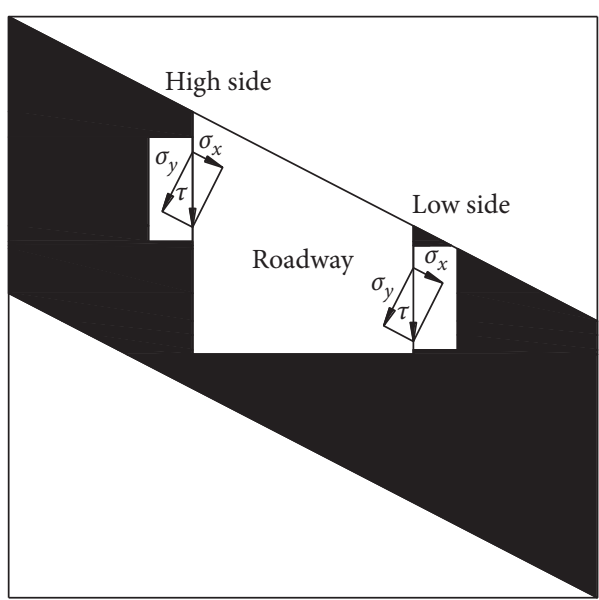

FIgURE 1: Stress decomposition map of the surrounding rock of two laneways.

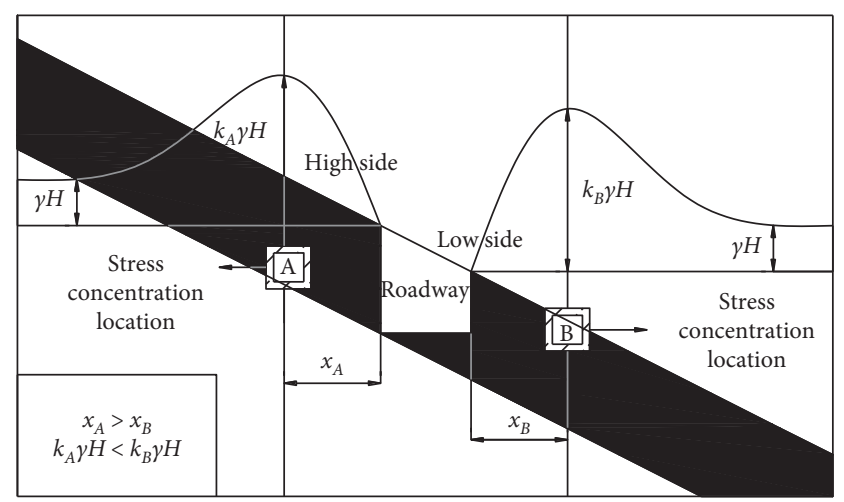

FIgURE 2: Stress distribution map of the surrounding rock of two laneways.

$$
\begin{aligned}
& x_{A}=\frac{m_{A} f}{2 \operatorname{tg} \varphi_{0}} \ln \left(\frac{k_{A} \gamma h+\left(c_{0} / \operatorname{tg} \varphi_{0}\right)}{\left(c_{0} / \operatorname{tg} \varphi_{0}\right)+\left(P_{x} / f\right)}\right), \\
& x_{B}=\frac{m_{B} f}{2 \operatorname{tg} \varphi_{0}} \ln \left(\frac{k_{B} \gamma h+\left(c_{0} / \operatorname{tg} \varphi_{0}\right)}{\left(c_{0} / \lg \varphi_{0}\right)+\left(P_{x} / f\right)}\right),
\end{aligned}
$$

where $x_{A}$ and $x_{B}$ are the widths of the stress limit equilibrium zone (m); $m_{A}$ and $m_{B}$ denote the height of the roadway $(\mathrm{m}) ; f$ is the lateral pressure coefficient; $\varphi_{0}$ is the friction angle of composite coal rock $\left(^{\circ}\right) ; k_{A}$ and $k_{B}$ denote the pressure rise coefficients; $h$ is the coal mining depth (m); $c_{0}$ is the cohesive force between the coal seam and roof rock stratum (MPa); $\gamma$ is the bulk density $(\mathrm{kg} \cdot \mathrm{m} 3)$; and $P_{x}$ is the support resistance to coal support (MPa).

It can be seen from equations (1) and (2) that the distances from the stress concentration areas $\mathrm{A}$ and $\mathrm{B}$ to the two walls play a key role in determining the heights of the two walls of the roadway. For the right-angled trapezoidal roadway in the inclined coal seam, the distance from the stress concentration area of the high side to the wall of the roadway is larger than that of the low side because of the obvious difference between the heights of the high and low sides. 
For the roof of the roadway, the stress distribution also exhibits obvious asymmetric characteristics; that is, the stress concentration of the right wall (low side) sharp angle of the roadway roof is greater than the left wall (high side) sharp angle, and it changes with the change in inclination, as shown in Figure 3. These values are calculated as follows:

$$
\begin{aligned}
\sigma_{w} L & =\int_{0}^{5 b_{1}} 5 a b_{1} \gamma_{1} h_{1} \mathrm{~d} h, \\
\sigma_{w} R & =\int_{0}^{6 b_{1}-b_{2}} 5 a\left(6 b_{1}-b_{2}\right) \gamma_{1} h_{1} \mathrm{~d} h,
\end{aligned}
$$

where $\sigma_{w} L$ and $\sigma_{w} R$ are the stresses at the corners of the high and low sides of the roadway roof (MPa), respectively; $a$ is the width of the roadway $(\mathrm{m}) ; \gamma_{1}$ is the average rock bulk density $\left(\mathrm{kg} \cdot \mathrm{m}^{3}\right) ; h_{1}$ is the coal mining depth $(\mathrm{m}) ; b_{1}$ and $b_{2}$ are the heights of the roadway in the high and low sides $(\mathrm{m})$, respectively.

In conclusion, under the asymmetric stress of the surrounding rock of the right angle trapezoid roadway in the inclined coal seam, the deformation and failure of the surrounding rock of roadway also presents obvious asymmetric characteristics. The two walls of the roadway are squeezed and dislocated on the inside and bulge out considerably. The damage on the low side is greater than that in the high side, and the greatest damage is observed in the two corners of the low side.

\section{Model Establishment and Parameter Selection}

Based on the Mohr Coulomb criterion, a numerical model is established using the numerical simulation software FLAC3D (Figure 4). The model size is $36 \mathrm{~m} \times 5 \mathrm{~m} \times 36 \mathrm{~m}$, the four walls are constrained in the normal direction, the top surface is the ground surface, and the surface is the free boundary of stress and displacement; the bottom boundary is subjected to horizontal and vertical constraints, and the top of the model is the overlying rock layer. Four typical calculation models with inclination angles of $18^{\circ}, 21^{\circ}, 24^{\circ}$, and $27^{\circ}$ were established, and stresses of $2.5 \mathrm{MPa}, 5 \mathrm{MPa}$, $10 \mathrm{MPa}, 15 \mathrm{MPa}$, and $20 \mathrm{MPa}$ were applied. The asymmetric distribution characteristics of surrounding rock stress in the right-angled trapezoidal roadway were analyzed. According to the coal seam geological conditions of the Shitanjing No. 2 mining area, the physical and mechanical parameters of the surrounding rock are selected as given in Table 1.

\section{Numerical Simulation Analysis}

4.1. Vertical Stress Distribution Characteristics of Roadway. Figure 5 shows the vertical stress nephogram of the rightangled roadway in different inclined seams under a simulated ground stress of $2.5 \mathrm{MPa}$. It can be seen from the figure that the stress concentration on the right wall (low side) of the roadway is greater than that on the left wall (high side). The distance from the stress concentration area of the left wall (high side) to the side of the roadway is greater than that of the right wall (low side). The stress concentration on the

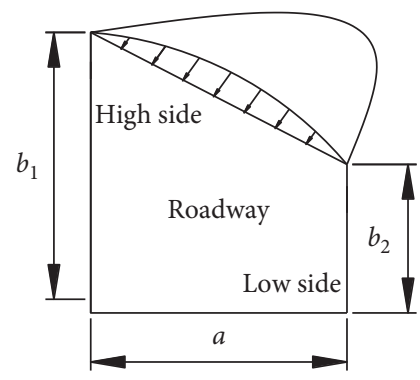

Figure 3: Stress distribution at the roof of the laneway.

roof of the roadway deviates toward the life wall (high side), and the stress concentration on the floor deviates toward the right wall (low side) and changes with the inclination angle.

Figure 6 is the curve of the stress concentration peak value of the right-angled trapezoidal roadway for different inclined seams with simulated ground stress $q$. Figure 6 displays that the stress concentration peak values of both walls of the roadway increases with the increase in inclination and ground stress. When the inclination angle is $18-27^{\circ}$, the stress concentration peak value of the low side is 1.07-1.33 times greater than that of the high side. However, under the action of small ground stress, the difference in peak stress between the two walls is not very obvious, mainly because of the influence of the dip angle.

Figure 7 is the curve of the distance from the peak stress concentration to both the walls of the right-angled trapezoidal roadway in the inclined coal seam with different ground stresses. The distances from the points at which the peak values of stress concentration occur on the two walls of the roadway to the sides of the roadway are obviously different and increase with the increase in inclination and ground stress, as shown in Figure 7 and Table 2. When the inclination is $18-27^{\circ}$ and the ground stress is $10 \mathrm{MPa}$, at the high side of the roadway, the stress concentration peak to the distance of the side wall of the roadway is $1.28-3.00 \mathrm{~mm}$ greater than that at the low side. When the ground stress is $10-20 \mathrm{MPa}$ and the inclination is $18^{\circ}$, at the high side of the roadway, the stress concentration peak to the side wall of the roadway is greater than that at the low side, which is $1.26-1.36 \mathrm{~mm}$. However, with the increase in inclination angle, the distances from the points with peak stress concentrations at the two sides to the walls of the roadway become progressively smaller.

4.2. Horizontal Stress Distribution Characteristics of the Roadway. Figure 8 shows the horizontal stress nephogram of the right-angled trapezoidal roadway in different inclined seams under a simulated ground stress of $2.5 \mathrm{MPa}$. It can be seen from Figure 8 that the two cusps symmetrical with the dip angle of the coal seam show an obvious compressive stress zone, while the opposite direction shows an obvious tensile stress zone, and the maximum values of the compressive and tensile stresses appear at the two cusps of the roof of the roadway. With the increase in inclination angle, the stress concentration at the corner of the roadway decreases. 

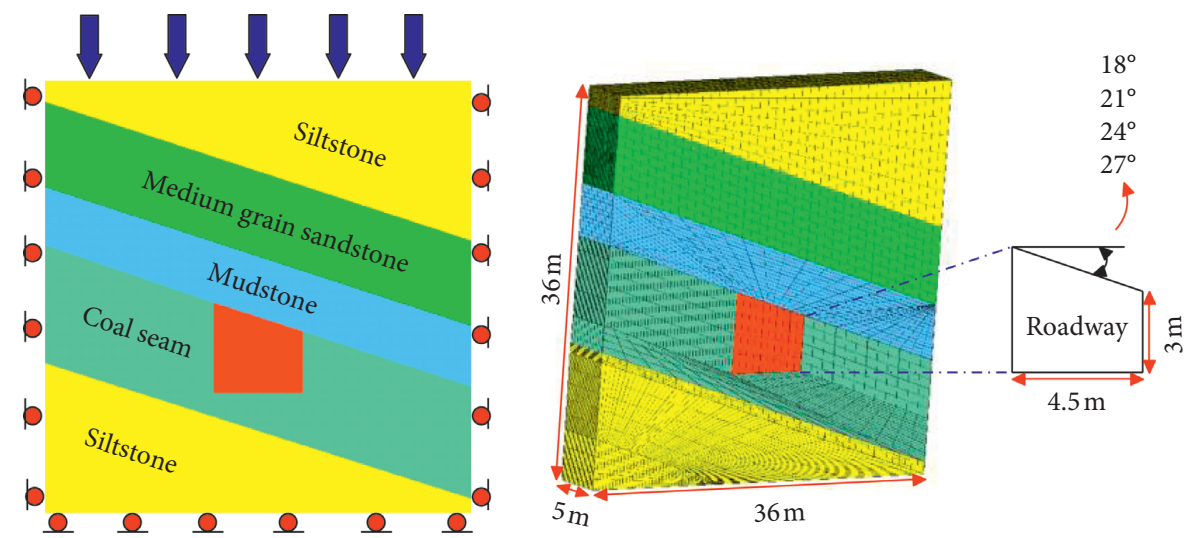

FIgURE 4: Numerical calculation model.

TABLE 1: Numerical simulation of physical and mechanical parameters of coal and rock.

\begin{tabular}{lccccccc}
\hline Rock stratum & $\begin{array}{c}\text { Thickness } \\
(\mathrm{m})\end{array}$ & $\begin{array}{c}\text { Density } \\
\left(\mathrm{kg} \cdot \mathrm{m}^{-3}\right)\end{array}$ & $\begin{array}{c}\text { Bulk modulus } \\
(\mathrm{GPa})\end{array}$ & $\begin{array}{c}\text { Shear modulus } \\
(\mathrm{GPa})\end{array}$ & $\begin{array}{c}\text { Friction } \\
\left({ }^{\circ}\right)\end{array}$ & $\begin{array}{c}\text { Cohesion } \\
(\mathrm{MPa})\end{array}$ & $\begin{array}{c}\text { Tension } \\
(\mathrm{MPa})\end{array}$ \\
\hline (1) Siltstone & 4.6 & 2460 & 8.49 & 6.47 & 32.1 & 5.7 & 3.77 \\
(2) Medium grain & 4 & 2510 & 10.11 & 7.27 & 37.0 & 11.8 \\
sandstone & 2.9 & 2530 & 7.79 & 5.34 & 31.5 & 1.85 & 2.78 \\
(3) Mudstone & 5.5 & 1400 & 1.80 & 0.83 & 21.0 & 1.60 & 1.54 \\
(4) Coal seam & 9.2 & 2460 & 8.49 & 6.47 & 32.1 & 5.7 \\
(5) Siltstone & & &
\end{tabular}

Stress $(\mathrm{Pa})$

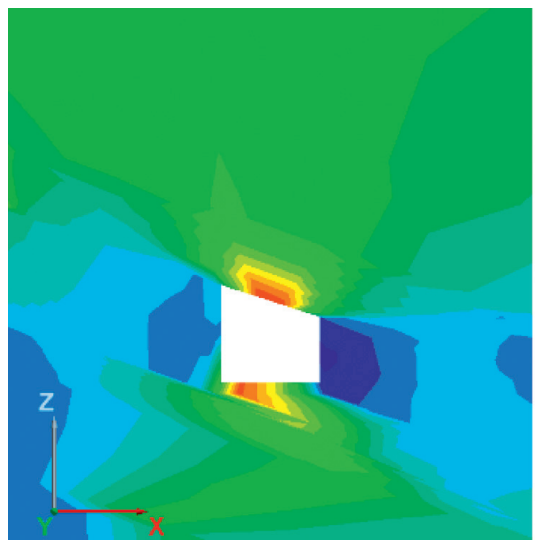

(a)

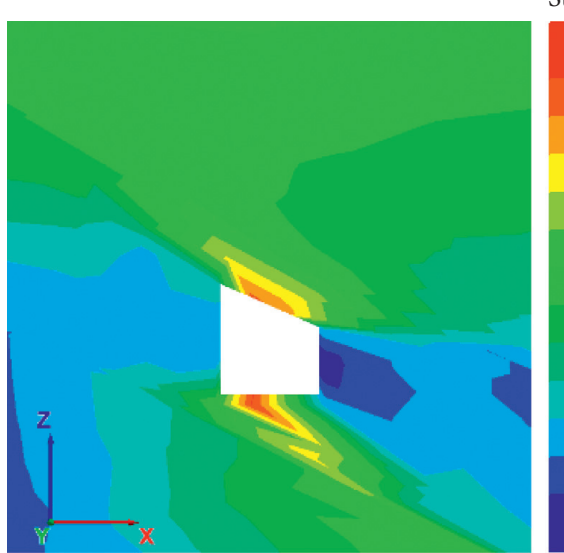

(c)

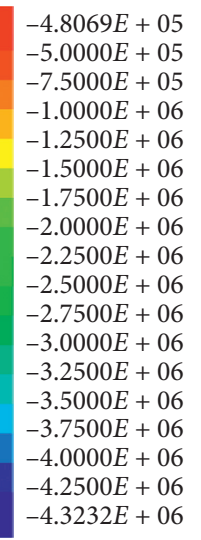

$4.3232 \mathrm{E}$

tress $(\mathrm{Pa})$

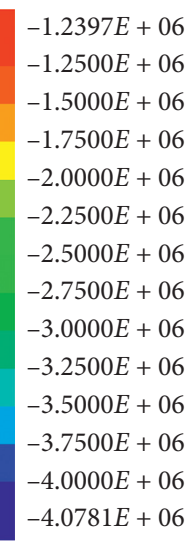

$-4.0781 E+06$
Stress $(\mathrm{Pa})$

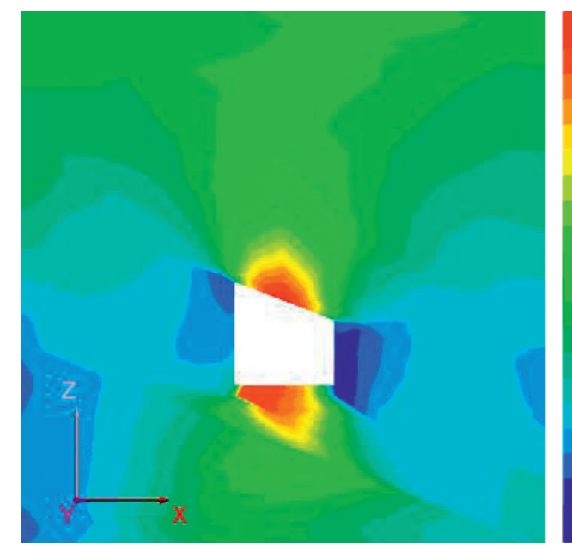

$9.9217 E+04$
$0.0000 E+00$
$-2.5000 E+05$
$-5.0000 E+05$
$-7.5000 E+05$
$-1.0000 E+06$
$-1.2500 E+06$
$-1.5000 E+06$
$-1.7500 E+06$
$-2.0000 E+06$
$-2.2500 E+06$
$-2.5000 E+06$
$-2.7500 E+06$
$-3.0000 E+06$
$-3.2500 E+06$
$-3.5000 E+06$
$-3.7500 E+06$
$-4.0000 E+06$
$-4.2500 E+06$
$-4.5000 E+06$
$-4.5879 E+06$

(b)

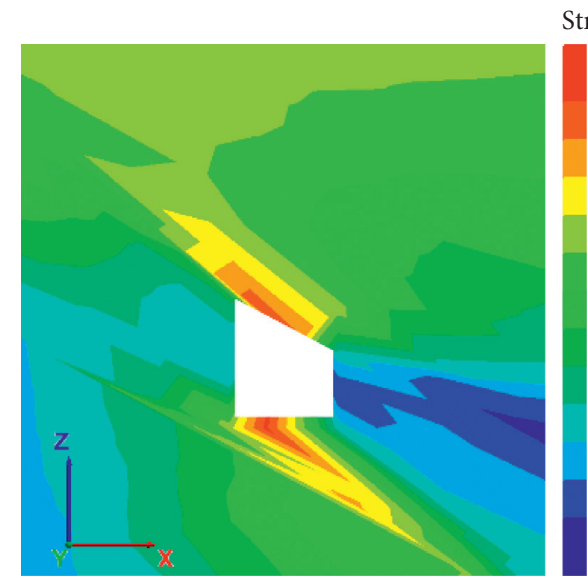

Stress $(\mathrm{Pa})$

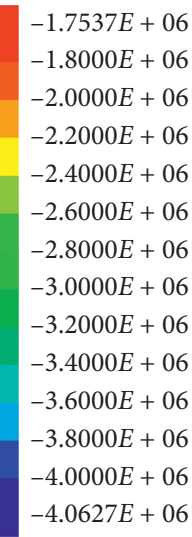

(d)

Figure 5: Vertical stress nephogram of the roadway. (a) $18^{\circ}$. (b) $21^{\circ}$. (c) $24^{\circ}$. (d) $27^{\circ}$. 


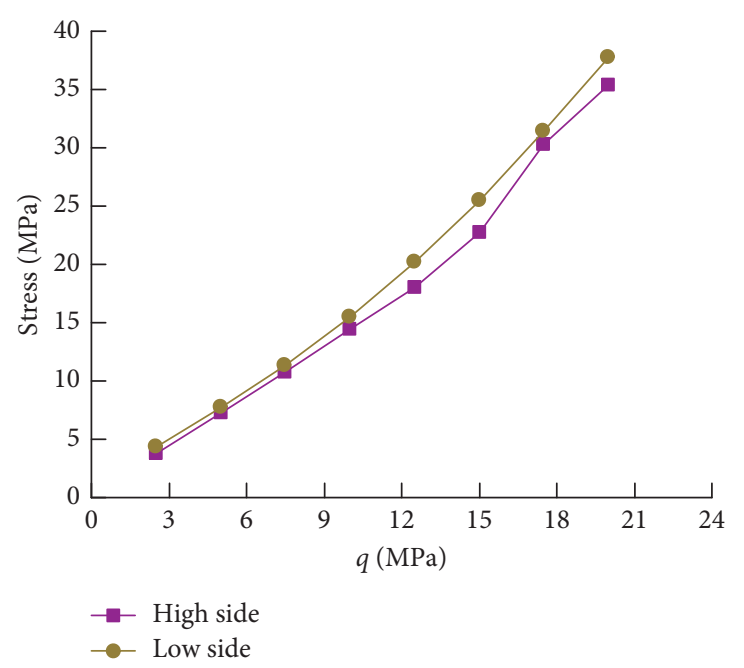

(a)

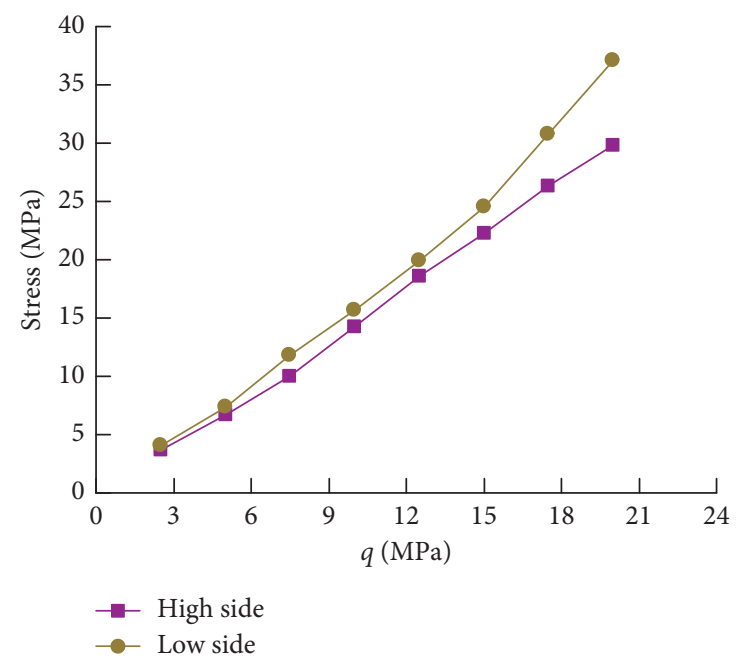

(c)

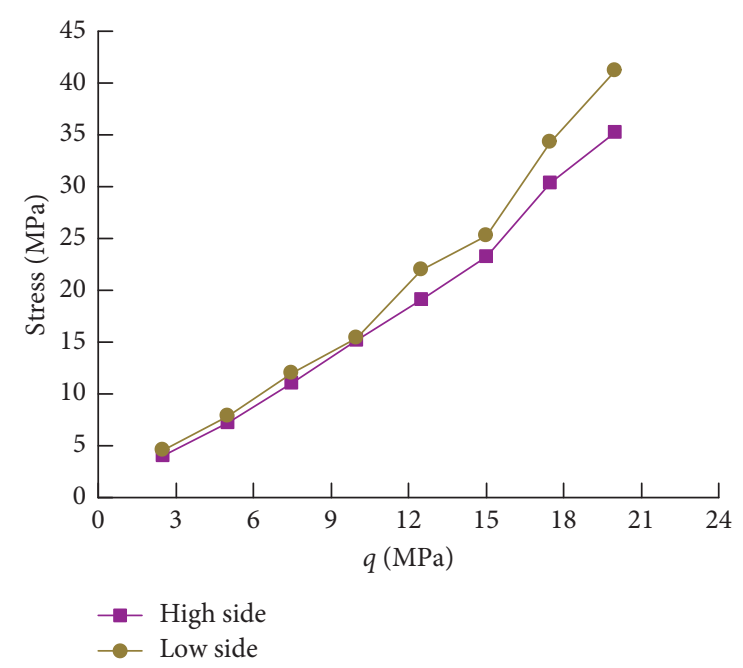

(b)

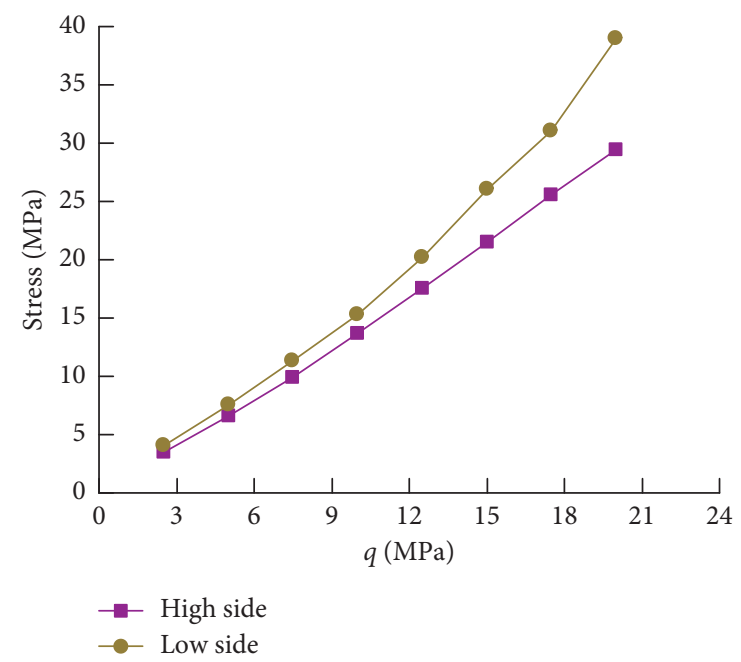

(d)

Figure 6: Comparative analysis curves of peak stress and ground stress of the two sides of the roadway. (a) $18^{\circ}$. (b) $21^{\circ}$. (c) $24^{\circ}$. (d) $27^{\circ}$.

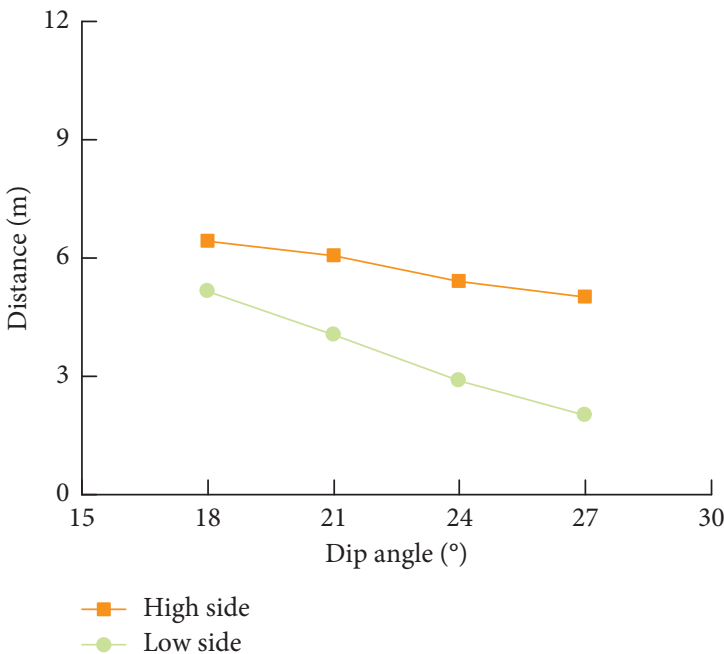

(a)

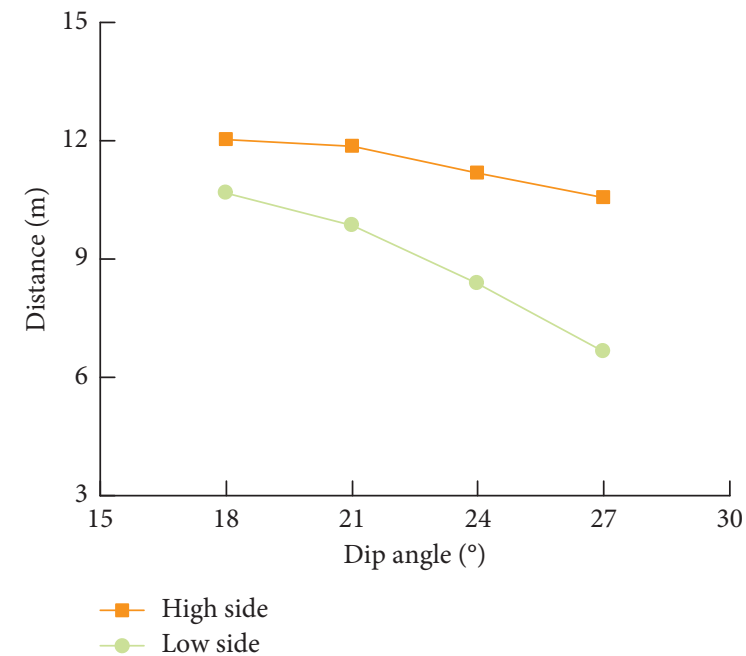

(b)

FIGURE 7: Curve of the change in stress concentration peak with the side distance of the two sides of the roadway with inclination angle. (a) $10 \mathrm{MPa}$. (b) $20 \mathrm{MPa}$. 
TABLE 2: Distance from peak stress concentration to both sides of roadway (mm).

\begin{tabular}{|c|c|c|c|c|}
\hline \multirow{2}{*}{ Dip angle } & \multicolumn{2}{|c|}{ Ground stress $10 \mathrm{MPa}$} & \multicolumn{2}{|c|}{ Ground stress $20 \mathrm{MPa}$} \\
\hline & Low side & High side & Low side & High side \\
\hline $18^{\circ}$ & 6.42 & 5.14 & 12.03 & 10.67 \\
\hline $21^{\circ}$ & 6.05 & 4.05 & 11.85 & 9.85 \\
\hline $24^{\circ}$ & 5.4 & 2.9 & 11.18 & 8.38 \\
\hline $27^{\circ}$ & 5.01 & 2.01 & 10.55 & 6.65 \\
\hline
\end{tabular}

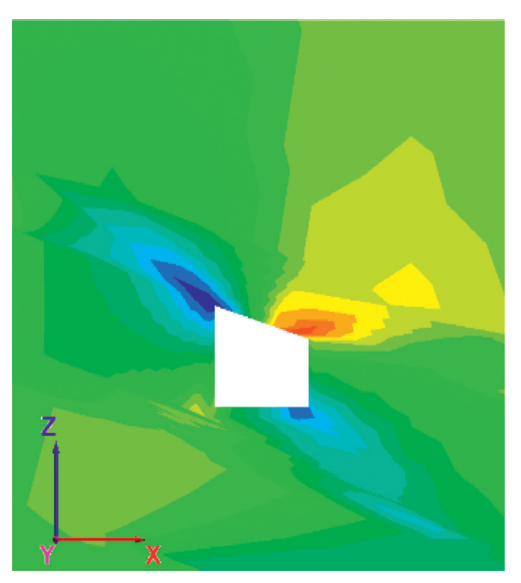

(a)

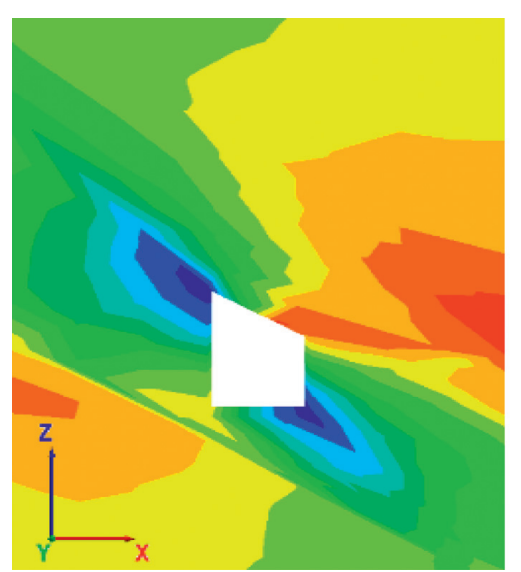

(c)
Stress $(\mathrm{Pa})$

$7.0522 E+05$
$7.0000 E+05$
$6.0000 E+05$
$5.0000 E+05$
$4.0000 E+05$
$3.0000 E+05$
$2.0000 E+05$
$1.0000 E+05$
$0.0000 E+00$
$-1.0000 E+05$
$-2.0000 E+05$
$-3.0000 E+05$
$-4.0000 E+05$
$-5.0000 E+05$
$-6.0000 E+05$
$-7.0000 E+05$
$-8.0000 E+05$
$-9.0000 E+05$
$-9.0594 E+05$

$-9.0594 E+05$

Stress $(\mathrm{Pa})$

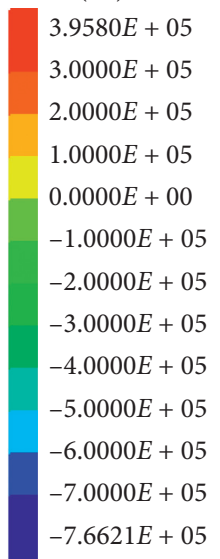

$-7.6621 E+05$

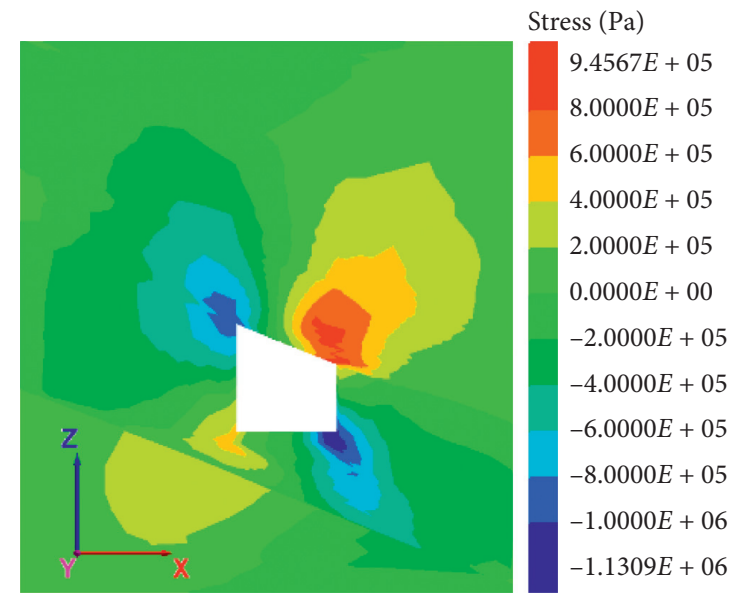

(b)

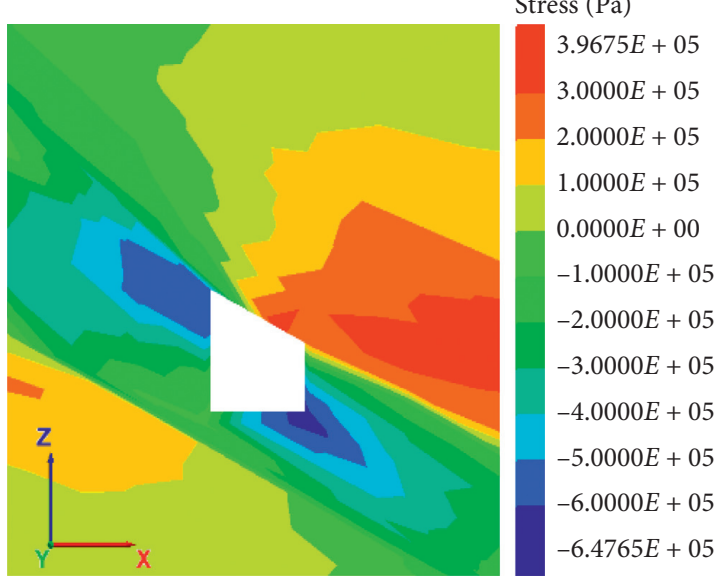

(d)

FIgURE 8: Horizontal stress distribution characteristics of the roadway. (a) $18^{\circ}$. (b) $21^{\circ}$. (c) $24^{\circ}$. (d) $27^{\circ}$.

\subsection{Horizontal Displacement Characteristics of the Roadway.} Figures 9 and 10 depict the horizontal stress nephogram of the roadway and the displacement analysis diagram of the two walls of the roadway with different simulated ground stresses $q$ and different inclination angles, respectively. Figures 9 and 10 and Table 3 reveal that the displacement difference between the two walls of the roadway is obvious and increases with the increase in group stress. The group stress is $10-15 \mathrm{MPa}$ and the inclination angle is $18^{\circ}$, and the roadway's high side is $15-77 \mathrm{~mm}$ larger than the low side. However, the difference decreases with the increase in inclination angle. When the inclination angle is $18-27^{\circ}$ and the group stress is $10 \mathrm{MPa}$, the roadway's high side is $15-10 \mathrm{~mm}$ larger than the low side. The main reason is that the difference in height between the two walls leads to uneven stress distribution.

\section{Validation of the Simulation Test}

5.1. Test Plan. To verify the asymmetric stress distribution characteristics of the surrounding rock of the right-angled trapezoidal roadway in the inclined seam further, the laboratory model test adopted the principle of geometric similarity and strength equality and established four types of right-angled trapezoidal roadway test models with different inclined seam angles, namely, $18^{\circ}, 21^{\circ}, 24^{\circ}$, and $27^{\circ}$ 
Displacement (m)

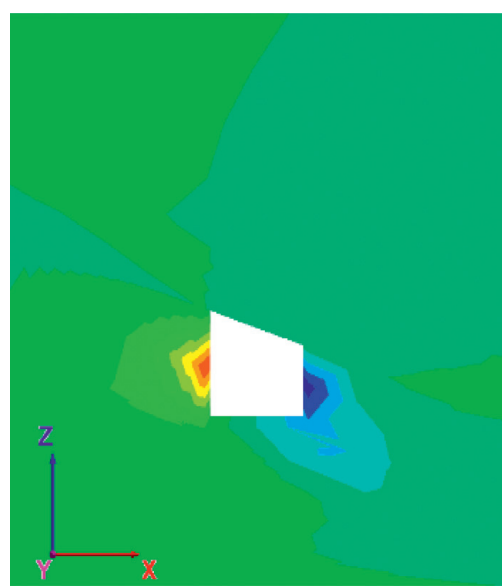

(a)

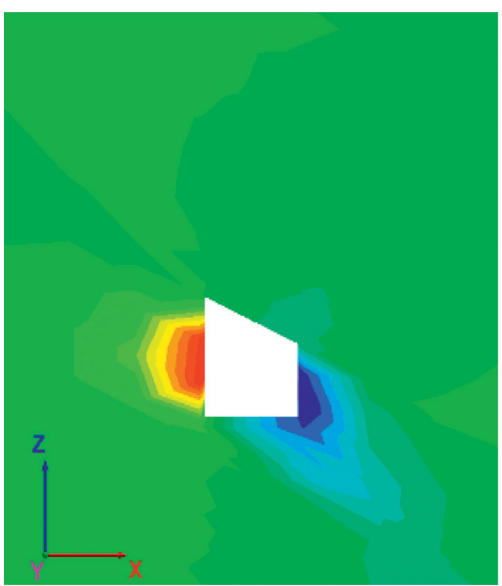

(c)

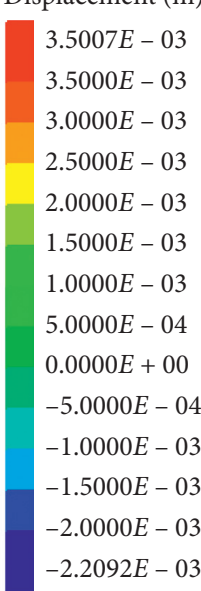

$-2.2092 E$

Displacement $(\mathrm{m})$

$2.6609 E-03$
$2.5000 E-03$
$2.2500 E-03$
$2.0000 E-03$
$1.7500 E-03$
$1.5000 E-03$
$1.2500 E-03$
$1.0000 E-03$
$7.5000 E-04$
$5.0000 E-04$
$2.5000 E-04$
$0.0000 E+00$
$-2.5000 E-04$
$-5.0000 E-04$
$-7.5000 E-04$
$-1.0000 E-03$
$-1.2500 E-03$
$-1.5000 E-03$
$-1.7500 E-03$
$-1.8776 E-03$

$-1.7500 E-03$
$-1.8776 E-03$
Displacement (m)

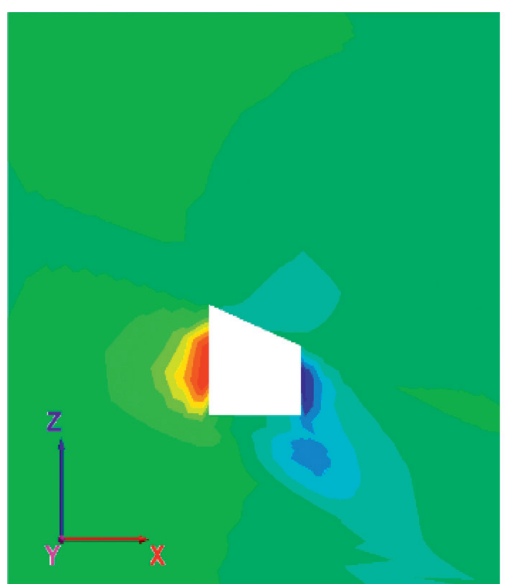

$2.1873 E-03$

$2.0000 E-03$

$1.7500 E-03$

$1.5000 E-03$

$1.2500 E-03$

$1.0000 E-03$

$7.5000 E-04$

$5.0000 E-04$

$2.5000 E-04$

$0.0000 E+00$

$-2.5000 E-04$

$-5.0000 E-04$

$-7.5000 E-04$

$-1.0000 E-03$

$-1.2500 E-03$

(b)

$-1.2767 E-03$

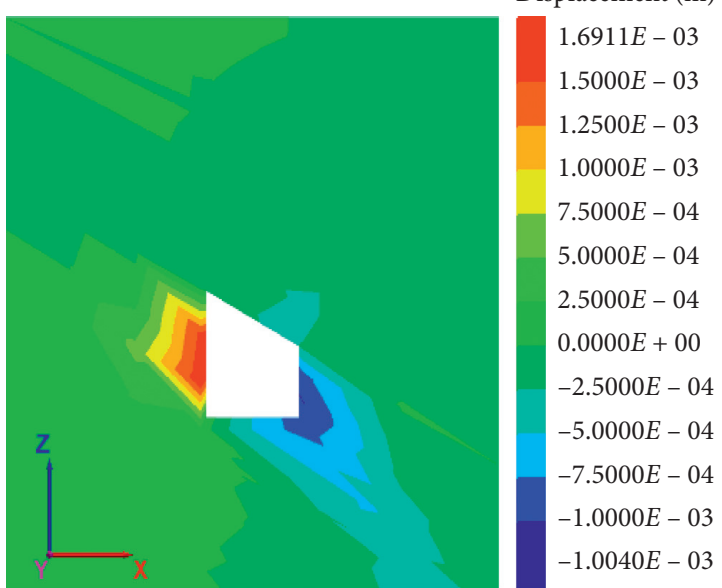

(d)

Figure 9: Horizontal stress distribution characteristics of the roadway. (a) $18^{\circ}$. (b) $21^{\circ}$. (c) $24^{\circ}$. (d) $27^{\circ}$.

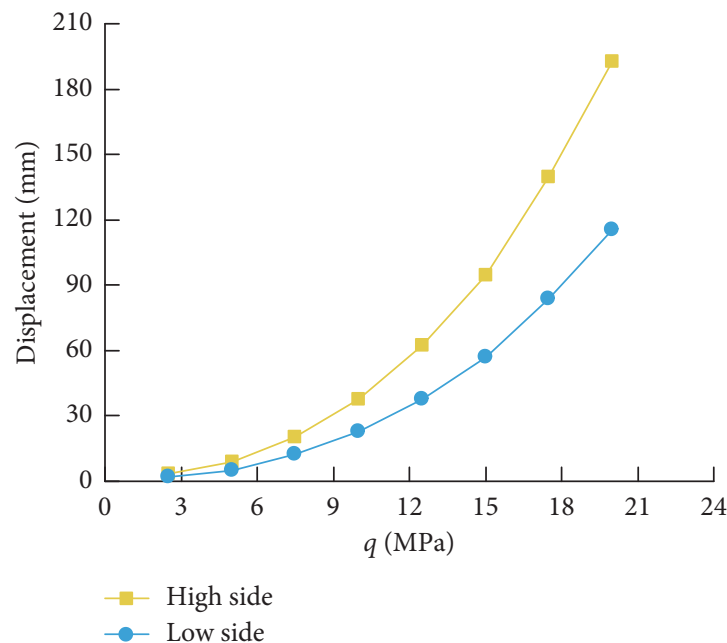

(a)

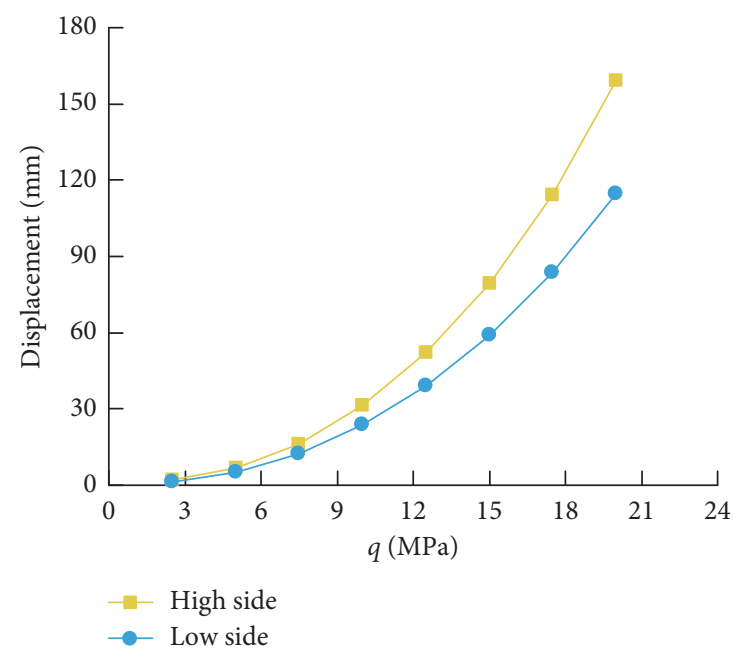

(b)

Figure 10: Continued. 


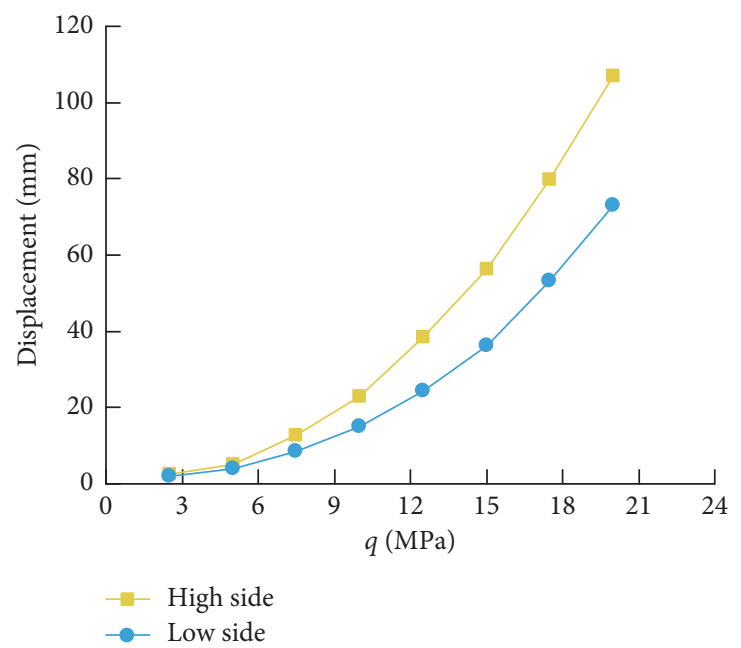

(c)

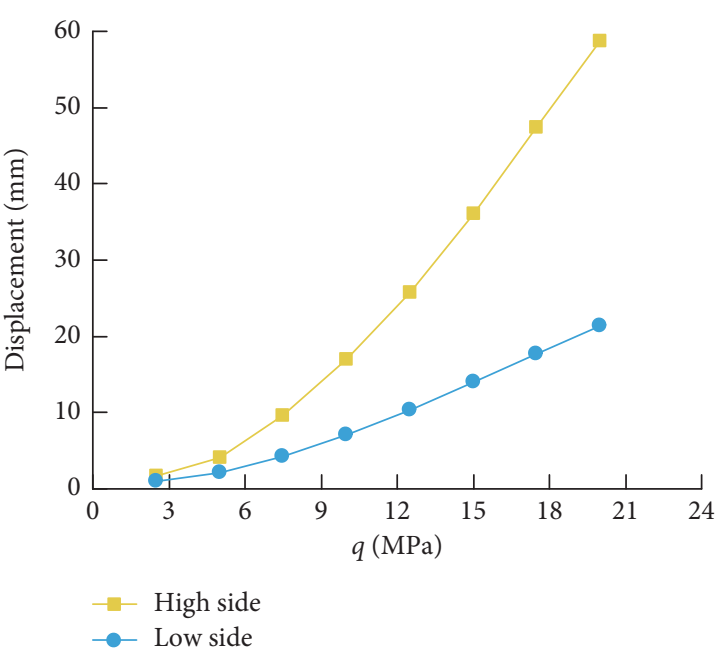

(d)

Figure 10: Analysis curves of the horizontal displacements of the two sides of the roadway. (a) $18^{\circ}$. (b) $21^{\circ}$. (c) $24^{\circ}$. (d) $27^{\circ}$.

TABLE 3: Horizontal displacement of two sides of roadway (mm).

\begin{tabular}{lcccc}
\hline \multirow{2}{*}{ Dip angle } & \multicolumn{2}{c}{ Ground stress $10 \mathrm{MPa}$} & \multicolumn{2}{c}{ Ground stress $20 \mathrm{MPa}$} \\
& Low side & High side & Low side & High side \\
\hline $18^{\circ}$ & 22.54 & 37.47 & 115.51 & 192.53 \\
$21^{\circ}$ & 23.89 & 31.31 & 114.64 & 159.00 \\
$24^{\circ}$ & 14.93 & 23.01 & 72.88 & 106.89 \\
$27^{\circ}$ & 7.1 & 17 & 21.41 & 58.81 \\
\hline
\end{tabular}

(Figure 11). The geometric similarity ratio is $1: 30$, the model size is $72 \mathrm{~cm} \times 72 \mathrm{~cm} \times 10 \mathrm{~cm}$, and the lithology parameters are selected from the engineering background of the Shitanjing No. 2 mining area, which is the same as that for the numerical simulation. Different proportions of cement mortar were used to simulate the characteristics.

The measurement points are arranged at the roadway walls, roof, and floor, as well as the corners. A vertical uniform load is applied to the model in a stepwise manner until the specimen is completely destroyed. The strain values of each measurement point under different loads are recorded in real time during the loading process.

\subsection{Analysis of Test Results}

5.2.1. Stress Distribution Law of the Roof Surrounding the Rock. Figure 12 displays a simulated ground stress-strain curve of the roof surrounding the rock of the trapezoidal roadway with different dip angles. The stress of the roof surrounding the rock of the roadway presents obvious asymmetric characteristics, and the size distribution of the middle measuring point of the roof (Intermediate) $>$ the low side measuring point of the roof $(\mathrm{R}$ - low side) $>$ the high side measuring point of the roof (R- high side) from Figure 12. In addition, the maximum strain on the low side of the surrounding rock is significantly larger than that on the high side. The greater the dip angle, the more obvious the difference in stress distribution between the high and low sides of the surrounding rock of the roadway. When the inclination angle is in the range of $18^{\circ}-27^{\circ}$, the maximum strain on the right wall of the roof (R- low side) is 1.3-2.1 times larger than that on the left wall of the roof ( $\mathrm{R}$ - high side).

5.2.2. Stress Distribution Law of the Surrounding Rocks of the Two Walls of the Roadway. Figure 13 describes the simulated ground stress-strain curve of the surrounding rock of the right-angled trapezoidal roadway with different dip angles. It can be concluded that the stress concentrations on the two walls of the roadway are clearly different, and they increase with increasing inclination and ground stress. The inclination angle is $18^{\circ}-27^{\circ}$, and the maximum value of the right wall (low side) stress concentration is 1.2-1.7 times that of the left wall (high side).

5.2.3. Stress Distribution Law of the Two Surrounding Rocks. Figure 14 is a simulated ground stress-strain curve of the surrounding rock at the corners of a right-angled trapezoidal roadway with different dip angles. Figure 14 reveals that the stress distribution of each point at the four corners of the roadway is different. From large to small, the order is low side shoulder angle (LSSA), high side shoulder angle (HSSA), low side bottom angle (LSBA), and high side bottom angle (HSBA). When the dip angle is $18^{\circ}$, LSSA's strain is $2-4$ times of other sharp angles, it changes with the change in inclination.

5.2.4. Analysis of Stress Distribution in the Surrounding Rock of the Roadway Floor. Figure 15 is a simulated ground stress-strain curve of the surrounding rock of a rectangular trapezoidal roadway with different dip angles. It can be seen from Figure 15 that under the action of the upper roof and the two sets of asymmetric stress, the stress distribution of the floor of the roadway also exhibits obvious asymmetry, 


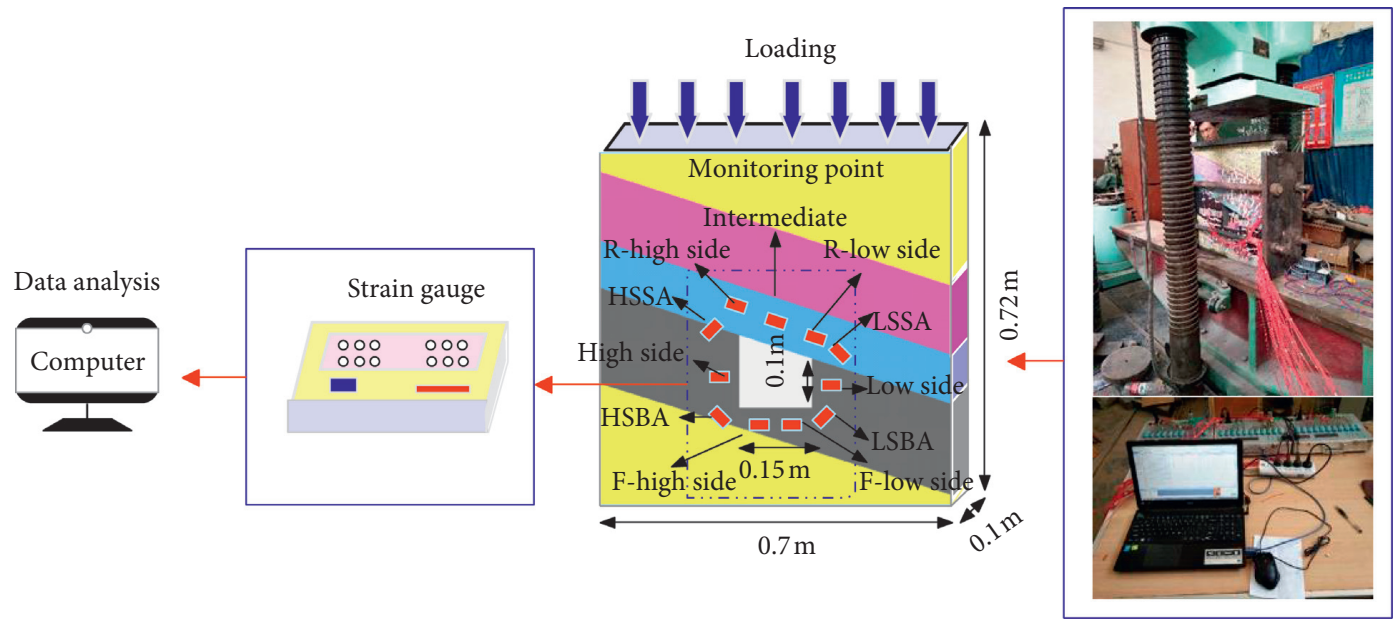

Figure 11: Test models of the right-angled trapezoidal roadway.

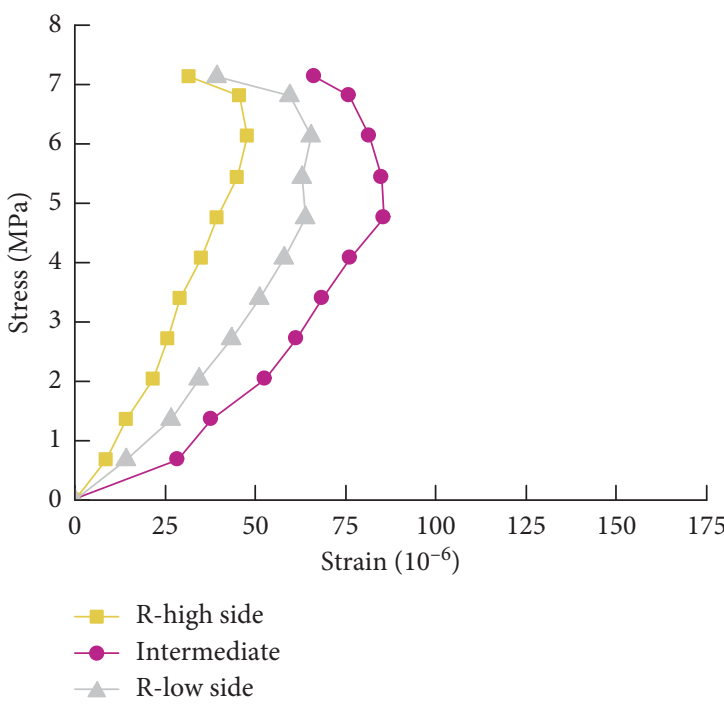

(a)

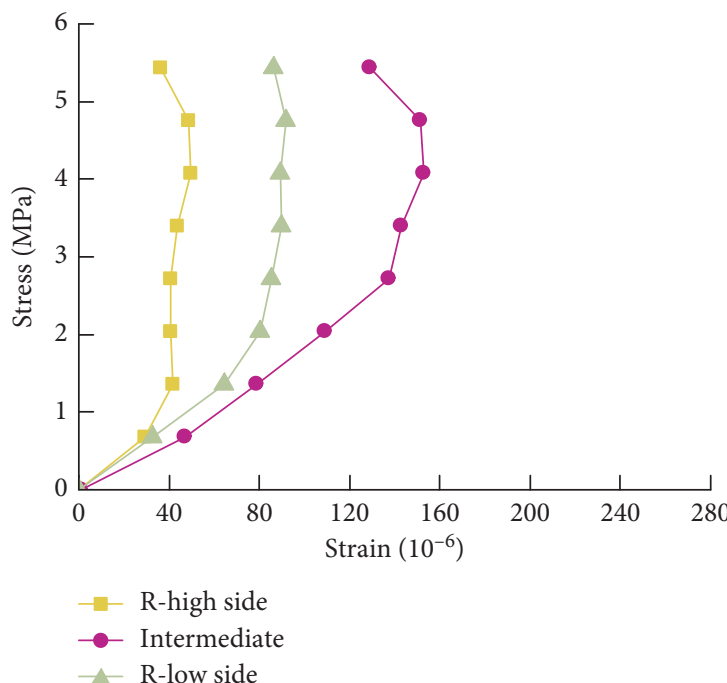

(c)

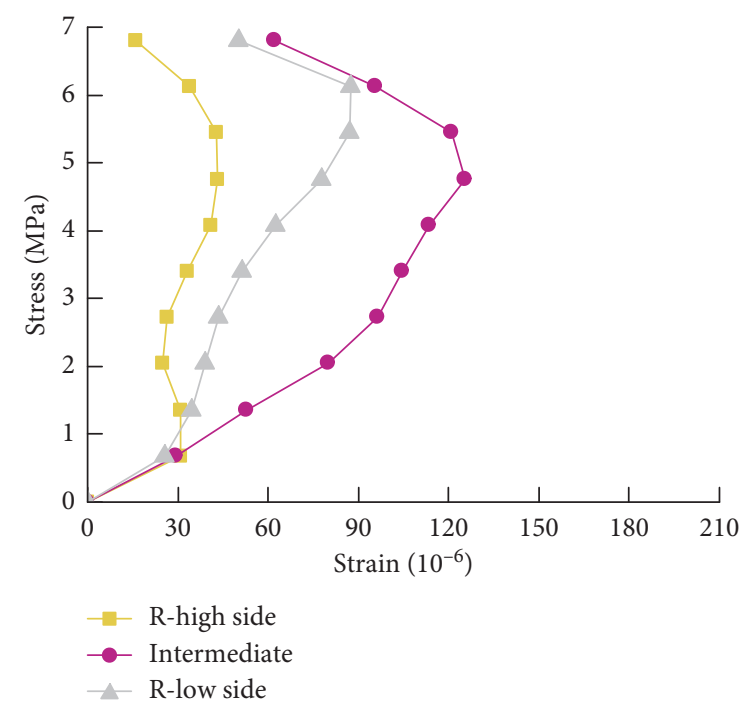

(b)

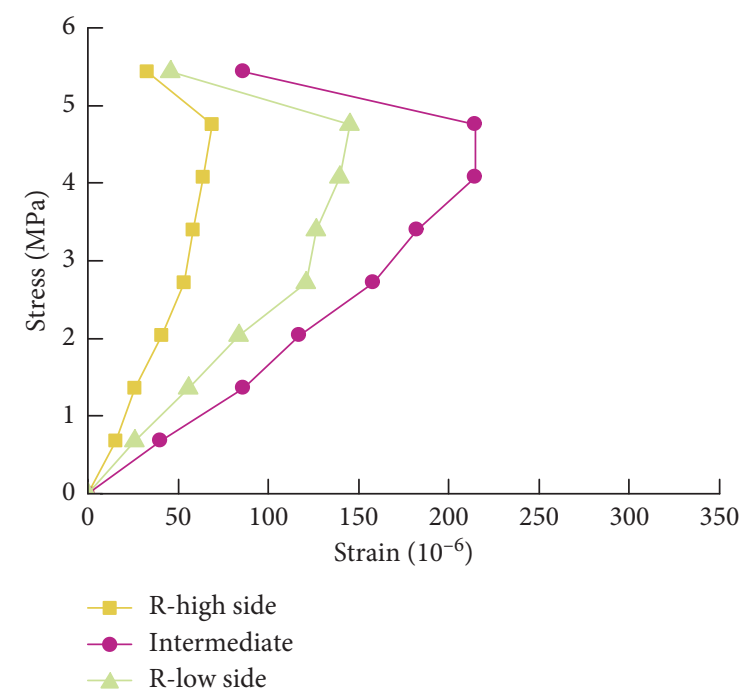

(d)

FIGURE 12: Stress-strain curves of the roof surrounding the rock. (a) $18^{\circ}$. (b) $21^{\circ}$. (c) $24^{\circ}$. (d) $27^{\circ}$. 

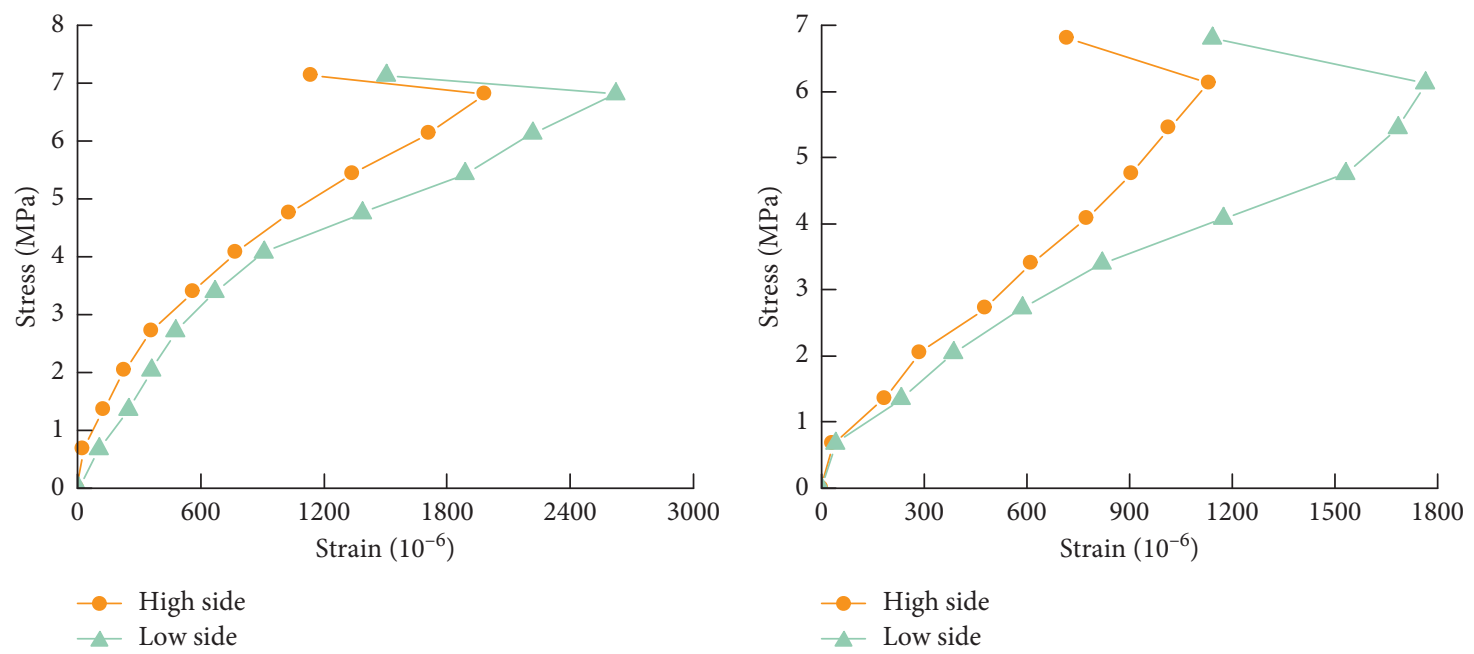

(a)

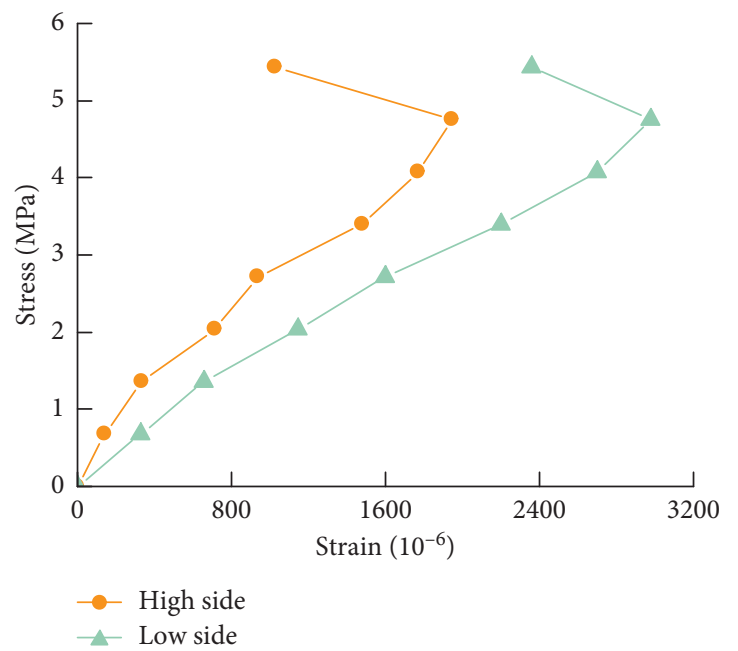

(c)

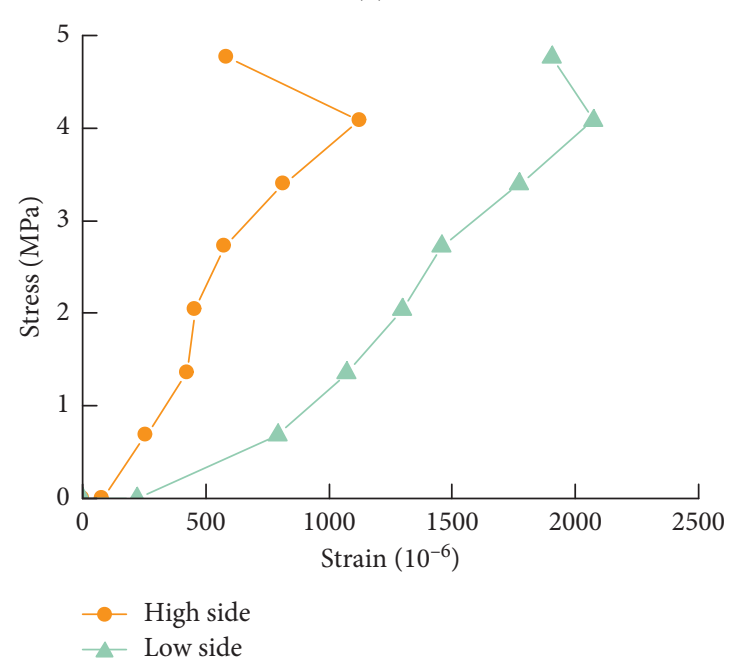

(d)

FIgURE 13: Stress-strain curve of the surrounding rock of the two sides of the roadway. (a) $18^{\circ}$. (b) $21^{\circ}$. (c) $24^{\circ}$. (d) $27^{\circ}$.
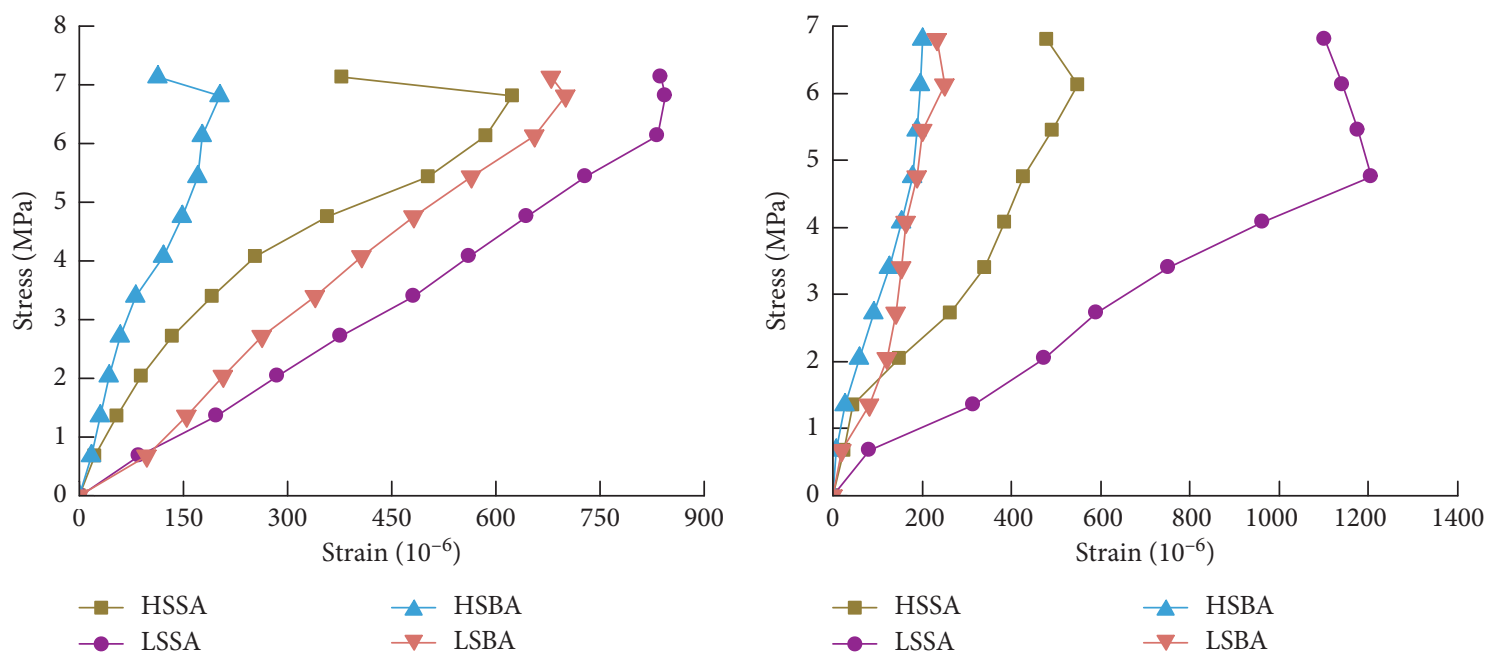

(a)

(b)

Figure 14: Continued. 


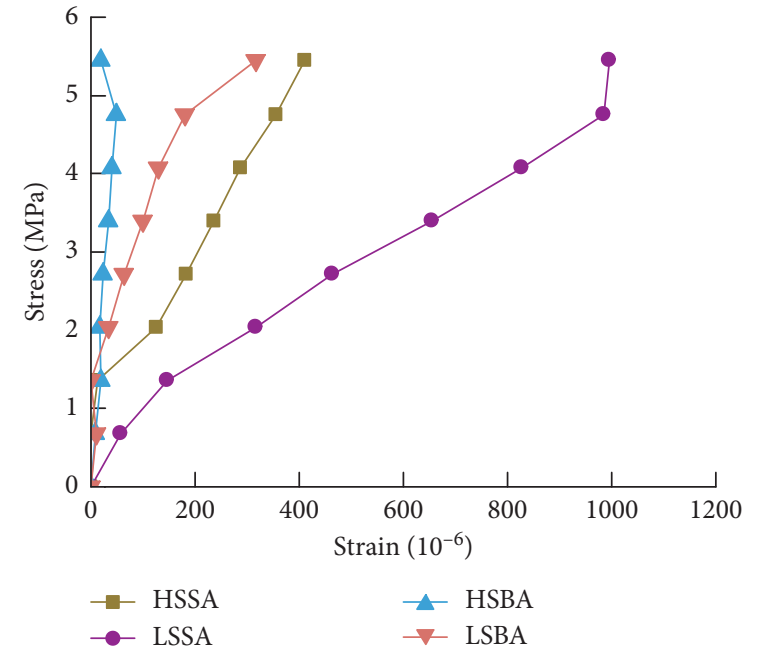

(c)

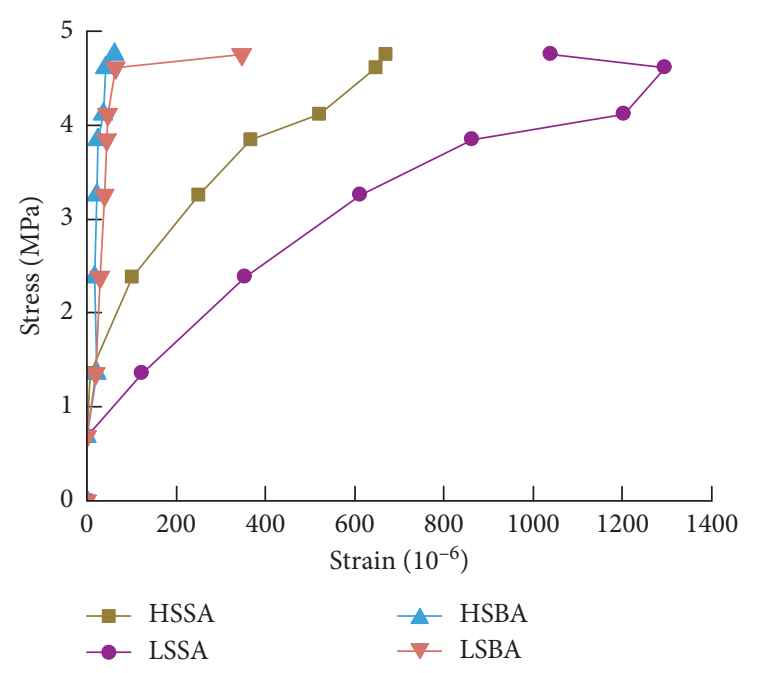

(d)

FIGURE 14: Stress-strain curve of the surrounding rock at the corner of the roadway. (a) $18^{\circ}$. (b) $21^{\circ}$. (c) $27^{\circ}$. (d) $27^{\circ}$.

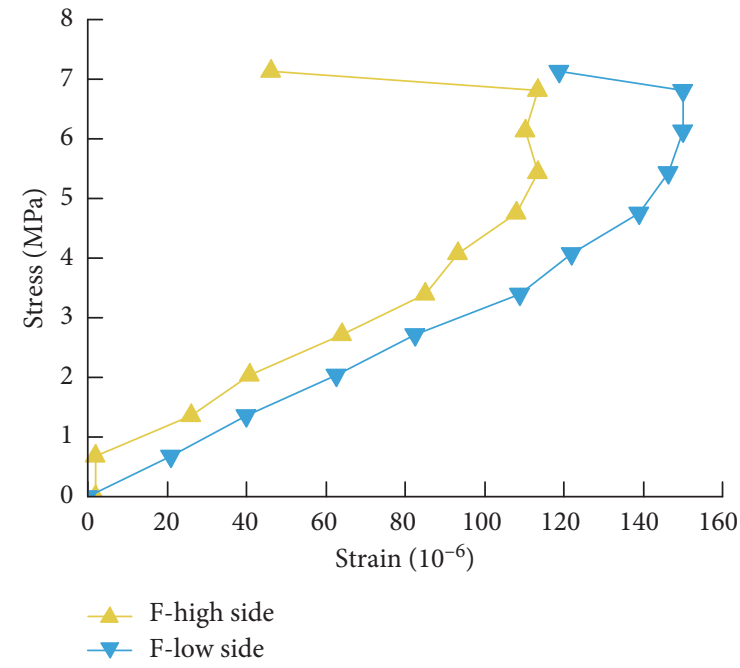

(a)

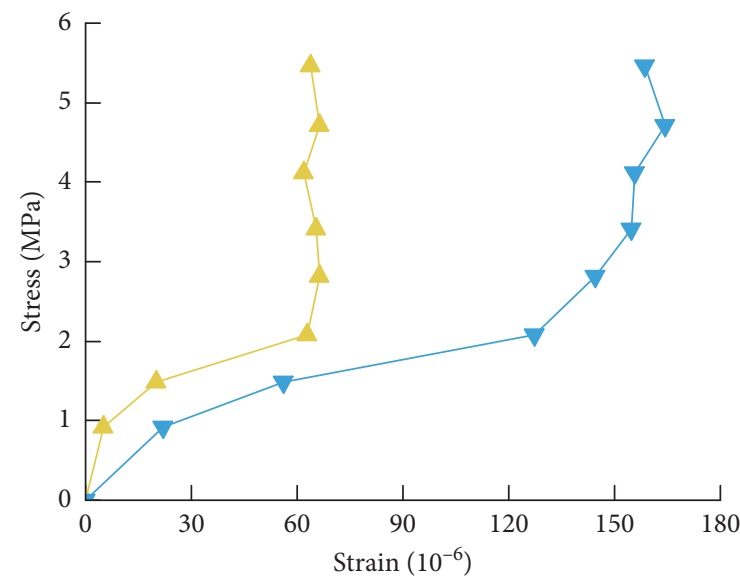

- F-high side

$\rightarrow$ F-low side

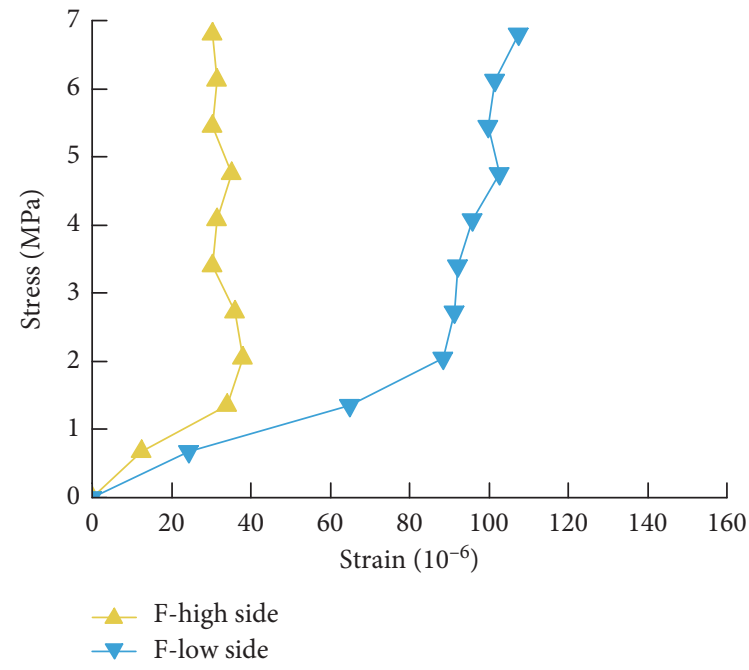

(b)

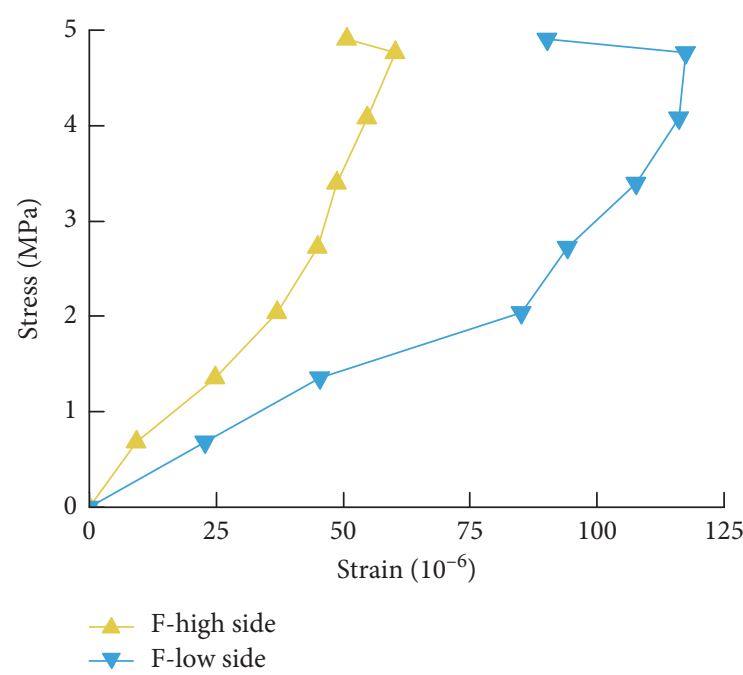

(d)

FIGURE 15: Stress-strain curve of roadway floor. (a) $18^{\circ}$. (b) $21^{\circ}$. (c) $24^{\circ}$. (d) $27^{\circ}$. 


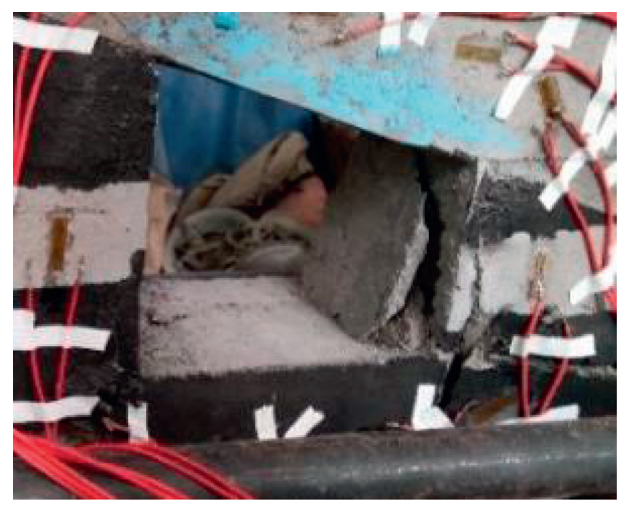

(a)

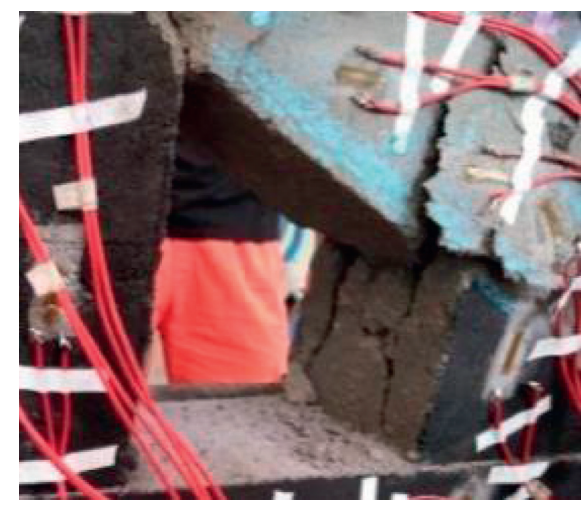

(b)

FIgURE 16: Deformation and failure of roadway in laboratory model test. (a) $24^{\circ}$. (b) $27^{\circ}$.

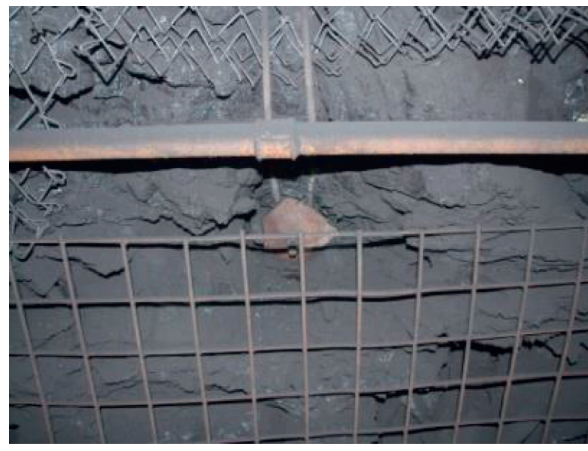

(a)

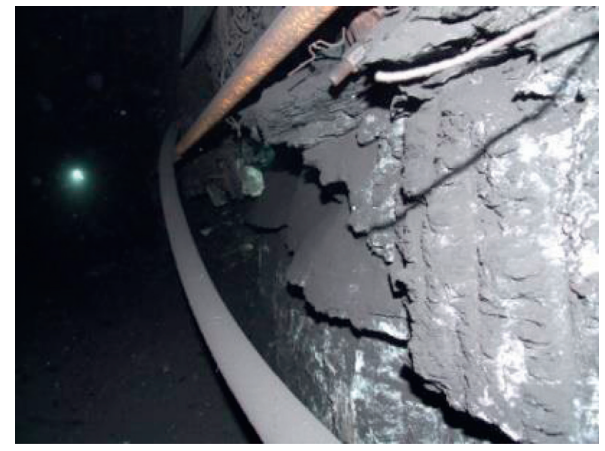

(b)

Figure 17: Deformation and failure of roadway in Shitanjing No. 2 mine. (a) $24^{\circ}$. (b) $27^{\circ}$.

and the stress on the right wall of the floor (F-low side) is greater than that on the left wall of the floor (F-high side).

From the laboratory model test results, it can be seen that the stress distribution law of the right-angled trapezoidal roadway in a gently inclined seam is similar to the numerical simulation, and the stress distribution of the surrounding rock in the roof, the two walls, the floor, and the corner of the roadway shows clear asymmetric characteristics; however, there are some differences in the numerical values. The main reason is that the proportion of similar materials, size of the model, loading mode, and so on have an impact on the test results.

\section{Comparison and Analysis of Simulation Results}

It can be seen from the simulation results that the asymmetric distribution law of the surrounding rock in inclined right angle trapezoidal roadway is basically the same as that of large dip angle and steep inclined coal seam roadway, but the degree of stress asymmetry in the inclined coal seam is much lower than that of large dip angle coal seam. The numerical simulation results of the asymmetric deformation and failure characteristics of the inclined trapezoidal roadway in the inclined coal seam are consistent with the laboratory model test (Figure 16) and the site failure morphology of the Shitanjing No. 2 mine (Figure 17), in which the deformation and failure law exhibits an asymmetrical feature. Further, the two walls of the roadway are severely bulging, and the low side is larger than the high side.

\section{Conclusion}

Based on the theory of asymmetric stress distribution in the surrounding rock of right-angled trapezoidal roadway in an inclined coal seam, and considering the Shijiajing No. 2 mining area as the engineering background, this paper further analyzes the asymmetric distribution characteristics of the surrounding rock by using the FLAC3D finite difference method. Through verifications with a simulation test, the following conclusions were drawn:

(1) The stress distribution of the surrounding rock of the right-angled trapezoidal roadway in the inclined coal seam shows clear asymmetry. The main performance is that the peak value of stress concentration in the low side is greater than that in the high side, and the distance between the high side and the side wall of the roadway is greater than that in the low side. With 
the increase in the inclination angle and ground stress, the difference between the peak value of stress concentration and the distance from the side wall of the roadway is more obvious. When the inclination angle is $18^{\circ}-27^{\circ}$, the peak value of stress concentration of the low side is $1.07-1.33$ times that of the high side, and the distance from the high side to the side wall of the roadway is $1.26-3.79 \mathrm{~m}$ larger than that of the low side. Second, two sharp corners that are symmetric with the same inclination angle of the coal seam show obvious compressive stress regions, while the opposite two sharp corners show obvious tensile stress regions. The maximum values of compressive and tensile stresses appear on the roof of the roadway.

(2) Under the action of asymmetric stress, the deformation and failure of the roadway surrounding the rock also presents asymmetric characteristics. The two walls of the roadway exhibit extrusion, dislocation, and serious deformation and damage; however, the deformation damage of the low side is obviously larger than that at the high side. The main reason is that the difference in height between the two walls of the roadway leads to the uneven distribution of stress.

(3) The results of numerical simulation are basically consistent with laboratory model test and field engineering. However, there are some differences in the data obtained, and the main reason is that the two are affected by the selection of the simulation parameters, ratio of similar materials, size of the model, and loading method.

\section{Data Availability}

The data used to support the findings of this study are included within the article.

\section{Conflicts of Interest}

The authors declare that they have no conflicts of interest regarding the publication of this paper.

\section{Acknowledgments}

This study was financially supported by the National Natural Science Foundation of China (51174159 and 59974019), the China Postdoctoral Science Foundation (2015M572580), and the Scientific Research Plan Projects of Education Department of Shanxi Province of China (15JK1471).

\section{Supplementary Materials}

Theoretical analysis process of roof stress distribution in inclined coal seam roadway. (Supplementary Materials)

\section{References}

[1] H. C. Li, "Study on deformation and failure characteristics and stability control of large dip angle thick compound roof roadway," Dissertation, Taiyuan University of Technology, Taiyuan, China, 2014.

[2] The National Development and Reform Commission, People's Republic of China Energy Development 11th Five-Year Plan, Beijing, China, 2007, in Chinese.

[3] K. Yu, L. Zhou, Q. Cao, and Z. Li, "Evolutionary game research on symmetry of workers' behavior in coal mine enterprises," Symmetry, vol. 11, no. 2, pp. 156-168, 2019.

[4] L. Si, Z. Wang, R. Xu, C. Tan, X. Liu, and J. Xu, "Image enhancement for surveillance video of coal mining face based on single-scale retinex algorithm combined with bilateral filtering," Symmetry, vol. 9, no. 6, pp. 93-108, 2017.

[5] F. L. He, M. G. Qian, and C. Y. Liu, Support System of Support and Surrounding Rock for High Productivity and High Efficiency Working Face, China Mining Industry Press, Xuzhou, China, 1997, in Chinese.

[6] S. J. Chen, Y. Wang, Y. Z. Wu, Z. Wang, and W. J. Zhang, "Coal resources and development potential in northwest China," Northwestern Geology, vol. 4, pp. 40-56, 2006, in Chinese.

[7] X. M. Sun and M. C. He, "Numerical simulation research on coupling support theory of roadway within soft rock at depth," Journal of China University of Mining and Technology, vol. 34, no. 2, pp. 166-169, 2005, in Chinese.

[8] S. X. Wei, J. H. Song, and H. W. Jing, "Numerical analysis of stress in the surrounding rock of the dynamic pressure tunnel with inclined seams," Metal Mine, vol. 41, no. 3, pp. 37-41, 2012, in Chinese.

[9] H. Wang, B. Xia, Y. Lu, T. Gong, and R. Zhang, "Study on the propagation laws of hydrofractures meeting a faulted structure in the coal seam," Energies, vol. 10, no. 5, pp. 654-672, 2017.

[10] J. Xie, J. Xu, and F. Wang, "Mining-induced stress distribution of the working face in a kilometer-deep coal mine-a case study in Tangshan coal mine," Journal of Geophysics and Engineering, vol. 15, no. 5, pp. 2060-2070, 2018.

[11] S. Zhang, X. Wang, G. Fan, D. Zhang, and C. Jianbin, "Pillar size optimization design of isolated island panel gob-side entry driving in deep inclined coal seam-case study of Pingmei No. 6 coal seam," Journal of Geophysics and Engineering, vol. 15, no. 3, pp. 816-828, 2018.

[12] Y. Yuan, S. Tu, F. Wang, X. Zhang, and B. Li, "Hydraulic support instability mechanism and its control in a fullymechanized steep coal seam working face with large mining height," Journal of the Southern African Institute of Mining and Metallurgy, vol. 115, no. 5, pp. 441-447, 2015.

[13] J. Sun, L. Wang, and G. Zhao, "Failure characteristics and confined permeability of an inclined coal seam floor in fluidsolid coupling," Advances in Civil Engineering, vol. 2018, Article ID 2356390, 12 pages, 2018.

[14] S. Gu, B. Jiang, G. Wang, H. Dai, and M. Zhang, "Occurrence mechanism of roof-fall accidents in large-section coal seam roadways and related support design for Bayangaole coal mine, China," Advances in Civil Engineering, vol. 2018, Article ID 6831731, 17 pages, 2018.

[15] H. Xie, M. Gao, R. Zhang, G. Peng, W. Wang, and A. Li, "Study on the mechanical properties and mechanical response 
of coal mining at $1000 \mathrm{~m}$ or deeper," Rock Mechanics and Rock Engineering, vol. 52, no. 5, pp. 1475-1490, 2019.

[16] Y. Fang, C. Xu, G. Cui, and B. Kenneally, "Scale model test of highway tunnel construction underlying mined-out thin coal seam," Tunnelling and Underground Space Technology, vol. 56, pp. 105-116, 2016.

[17] M. C. He, "Physical modeling of an underground roadway excavation in geologically $45^{\circ}$ inclined rock using infrared thermography," Engineering Geology, vol. 121, no. 3-4, pp. 165-176, 2011.

[18] W. Gong, Y. Peng, M. He, and J. Wang, "Thermal image and spectral characterization of roadway failure process in geologically $45^{\circ}$ inclined rocks," Tunnelling and Underground Space Technology, vol. 49, pp. 156-173, 2015.

[19] H. Yang, S. Cao, Y. Li, C. Sun, and P. Guo, "Soft roof failure mechanism and supporting method for gob-side entry retaining," Minerals, vol. 5, no. 4, pp. 707-722, 2015.

[20] L. Q. Ma, Y. Zhang, D. S. Zhang, X. Q. Cao, Q. Q. Li, and Y. B. Zhang, "Support stability mechanism in a coal face with large angles in both strike and dip," Journal of the Southern African Institute of Mining and Metallurgy, vol. 115, no. 7, pp. 599-606, 2015.

[21] M. Jawed and R. K. Sinha, "Design of rhombus coal pillars and support for roadway stability and mechanizing loading of face coal using SDLs in a steeply inclined thin coal seam-a technical feasibility study," Arabian Journal of Geosciences, vol. 11, no. 15, pp. 415-429, 2018.

[22] Y. Yin, J. Zou, Y. Zhang, Y. Qiu, and K. Fang, "Experimental study of the movement of backfilling gangues for goaf in steeply inclined coal seams," Arabian Journal of Geosciences, vol. 11, no. 12, pp. 318-326, 2018.

[23] L. Q. Zhu and Y. Zhang, "Analysis of spontaneous combustion "three zones" in 3237 working face of zhaogezhuang mine," Applied Mechanics and Materials, vol. 71-78, pp. 1978-1982, 2011.

[24] S. Q. He, D. Z. Song, Z. L. Li et al., "Precursor of spatiotemporal evolution law of MS and AE activities for rock burst warning in steeply inclined and extremely thick coal seams under caving mining conditions," Rock Mechanics and Rock Engineering, no. 2, pp. 1-21, 2019.

[25] H. S. Tu, S. H. Tu, Y. Yuan, F. T. Wang, and Q. S. Bai, "Present situation of fully mechanized mining technology for steeply inclined coal seams in China," A rabian Journal of Geosciences, vol. 8, no. 7, pp. 1978-1982, 2015.

[26] W. Lv, Y. Wu, L. Ming, and J. Yin, "Migration law of the roof of a composited backfilling longwall face in a steeply dipping coal seam," Minerals, vol. 9, no. 3, pp. 188-203, 2019.

[27] Z. Bei, S. G. Cao, L. G. Wang, and Y. L. Lu, "Deformation failure mechanism and support measurements in roadway of steeply inclined coal seam," Journal of Mining \& Safety Engineering, vol. 28, no. 2, pp. 214-219, 2011.

[28] M. Z. Gao and H. Q. Jing, "Mechanical analysis of asymmetric floor heave of roadway," Journal of Anhui University of Science and Technology, vol. 32, no. 4, pp. 38-43, 2012, in Chinese.

[29] J. G. Liu, A. Y. Cao, Z. M. Yu, G. C. Jing, and H. Y. Liu, "Study on stress characteristics of roadway's sides in deep and inclined seam," China Coal, vol. 42, no. 8, pp. 30-34, 2016, in Chinese.

[30] X. H. Qi, "Study on deformation characters and support parameters of large angle seam roadway rock around," Dissertation, Xi'an University of Science and Technology, Xi'an, China, 2015, in chinese. 